\title{
Monoclonal Antibodies Reveal Novel Aspects of the Biochemistry and Organization of Olfactory Neurons Following Unilateral Olfactory Bulbectomy ${ }^{1}$
}

\author{
JAMES L. HEMPSTEAD AND JAMES I. MORGAN ${ }^{2}$ \\ Department of Physiological Chemistry and Pharmacology, Roche Institute of Molecular Biology, Roche Research Center, \\ Nutley, New Jersey 07110
}

\begin{abstract}
Following unilateral olfactory bulbectomy in rats the ipsilateral olfactory neuroepithelium undergoes degeneration. Subsequently, the receptor neuron complement of the tissue is restored by the proliferation and differentiation of immature neuroblasts. However, as noted by other workers, in the absence of a target organ the dynamics of neuron regeneration is altered such that there is an overall reduction in the number of cells positive for the olfactory marker protein when cellular equilibrium is re-established. Immunocytochemical staining of the olfactory epithelium of unilaterally bulbectomized rats with a series of anti-neuronal monoclonal antibodies reveals an attenuation of binding of some antibodies to the neurons of the ipsilateral epithelium. In contrast, other antineuronal monoclonal antibodies show no difference in staining intensity when ipsilateral and control contralateral epithelia are compared. These data suggest that the expression of some neuronal antigens is subject to control by the target olfactory bulb, whereas others are independent of such putative regulation. Besides altering the expression of some antigenic determinants, olfactory bulbectomy also results in certain organizational changes in epithelium. First, bulbectomy produces an increase in the incidence of a cell type that appears to span the neuroepithelium. Although the morphology of these cells is more akin to a sustentacular cell than to a receptor neuron, they are not immunoreactive with antibodies to sustentacular cells. The cells are stained, however, by an anti-neuronal antibody, NEU-9. The second aspect of altered organization is the appearance of novel olfactory marker protein-positive structures in the olfactory mucosa. These structures appear to be misplaced axonal bundles or nerve tangles and are reactive with a range of monoclonal antibodies to olfactory neurons but not antibodies to other cell types of the epithelium.
\end{abstract}

The receptor neuron population of the olfactory epithelium undergoes constant turnover (Graziadei, 1973), adult neurons being lost through death and their place being taken by new neurons produced by the differentiation of precursor neuroblasts termed basal cells (Graziadei and Metcalf, 1971; Moulton, 1974; Harding et al., 1977;

Received August 3, 1984; Revised February 8, 1985;

Accepted March 13, 1985

\footnotetext{
${ }^{1}$ We wish to thank Dr. Frank Margolis for the olfactory marker protein antiserum utilized in this study.

${ }^{2}$ To whom correspondence should be addressed.
}

Graziadei and Monti Graziadei, 1978). Concomitant with the differentiation of basal cells to receptor neurons is the induction of an $18.5-\mathrm{kD}$ acidic protein, the olfactory marker protein (OMP), unique to olfactory receptor neurons (Margolis, 1975; Farbman and Margolis, 1980; Monti Graziadei et al., 1980). Following various forms of chemical or surgical lesioning there ensues the precipitous death of essentially all adult neurons after which the tissue is regenerated by basal cell differentiation (Nagahara, 1940; Graziadei, 1973; Harding, 1977; Graziadei and Monti Graziadei, 1978). One form of lesion that leads to this series of events is removal of the target organ for olfactory receptor ncurons, the olfactory bulb (Ferriero and Margolis, 1975; Harding and Margolis, 1976; Graziadei et al., 1978; Constanzo and Graziadei, 1983; Monti Graziadei, 1983). Following regeneration of the olfactory neuroepithelium after olfactory bulbectomy, there are fewer neurons expressing immunocytochemically demonstrable OMP (Monti Graziadei, 1983), and the total tissue content of this receptor neuron-specific protein is also reduced (Harding and Margolis, 1976). This finding is in contrast to simple olfactory nerve transection where normal levels of OMP are observed when regeneration is complete (Harding and Margolis, 1976). Since OMP production by olfactory neurons in culture also seems to be modulated by the target olfactory bulb (Chuah and Farbman, 1983), this has led to the notion that the differentiation of the epithelial neuroblasts is controlled by signals originating in the bulb (Harding et al., 1977; Farbman and Margolis, 1980; Monti Graziadei et al., 1980; Chuah and Farbman, 1983). However, recent evidence would indicate that olfactory neuroblasts can differentiate to receptor neurons after long periods of time in various ectopic sites (Morrison and Graziadei, 1983), and olfactory neurons may even synthesize OMP when transplanted to the anterior chamber of the eye (Barber et al., 1982; Heckroth et al., 1983). Furthermore, the presence of OMP-synthesizing neurons in the ipsilateral epithelium of olfactory bulbectomized rats has been taken as specific evidence for a lack of control of OMP expression by the olfactory bulb (Monti Graziadei, 1983).

Since there is some dichotomy of opinion regarding the relative role played by the olfactory bulb in neuroblast differentiation and OMP expression by the olfactory neurons, we have attempted to derive further markers for the olfactory epithelium (Hempstead and Morgan, 1983a, b). In this study we report the use of a panel of antineuronal monoclonal antibodies (Hempstead and Morgan, 1985) in probing the biochemical and organizational sequelae of unilateral olfactory bulbectomy on the olfactory epithelium of rat. We demonstrate (1) the presence of neuronal antigenic determinants that are subject to modulation by the target olfactory bulb and (2) alterations in the cellular organization of the ipsilateral epithelium.

\section{Materials and Methods}

Monoclonal antibodies to the rat olfactory epithelium were originally produced by fusing spleen cells from BALB/c mice that had been immunized 

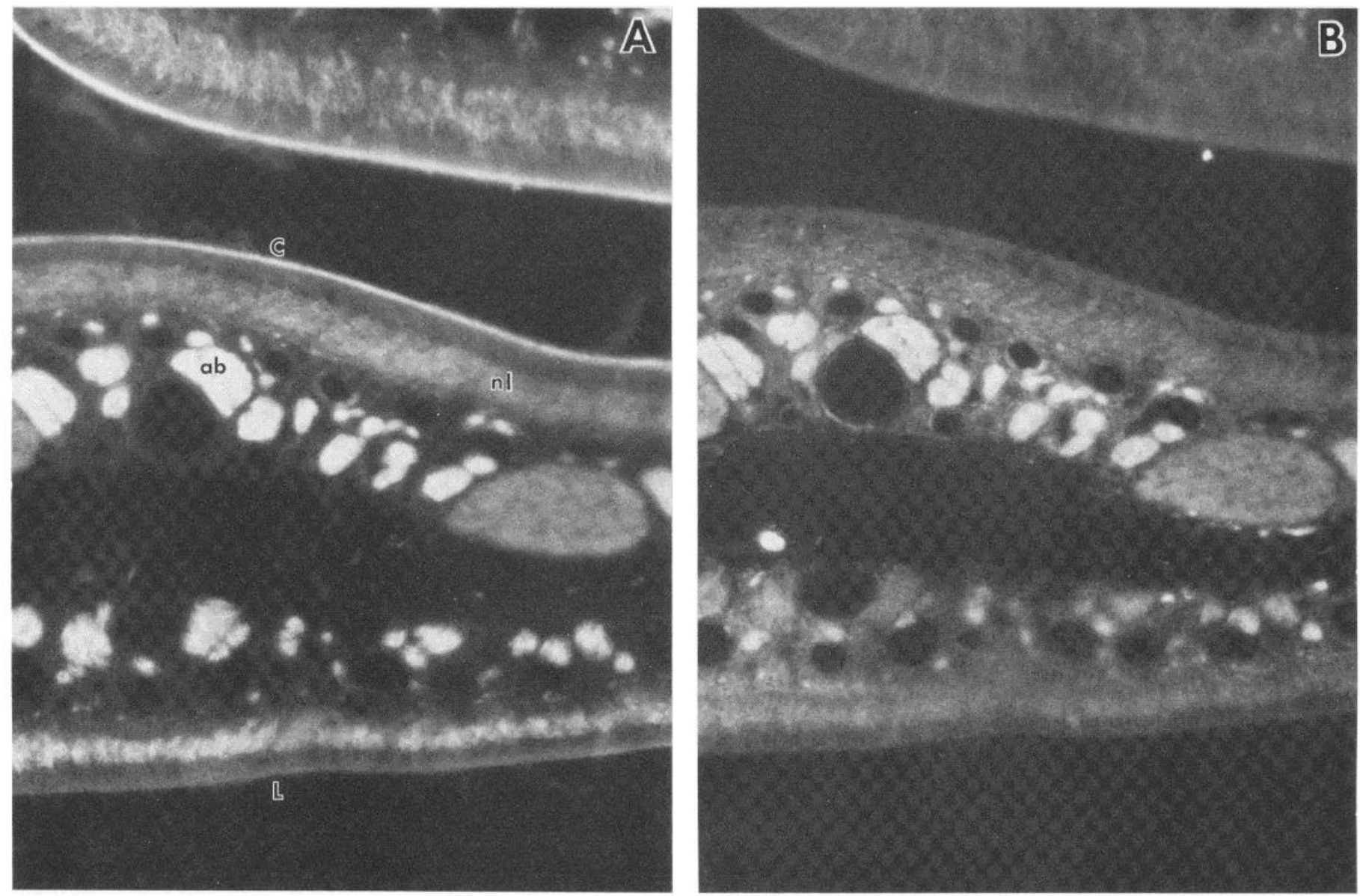

Figure 1. The staining characteristics of monoclonal antibody NEU-4 on rat olfactory epithelium. Sixteen weeks following unilateral olfactory bulbectomy the rat was sacrificed and its olfactory epithelium was processed for immunocytochemistry as described previously (Hempstead and Morgan, 1983a). $A$ shows staining for the OMP using fluorescein-conjugated goat anti-rabbit immunoglobulin as reporter, and $B$ shows the staining of NEU-4 monoclonal antibody using a trimethylrhodamine-conjugated goat anti-mouse immunoglobulin reporter. The photomicrograph depicts the olfactory mucosa at a position spanning the central septum separating control $(C)$ from bulbectomized $(L)$ epithelium. The olfactory receptor neuron layer $(n l)$ and axonal bundles $(a b)$ may be seen to be reactive with the OMP antiserum. In the lesioned side of the epithelium the receptor layer is thinner as marked by OMP and NEU-4 and, whereas the staining of axonal bundles becomes punctate and more diffuse, with the OMP antiserum they almost disappear with regard to NEU-4. Magnification $\times 150$.

with rat epithelium with PAI-O myeloma (Hempstead and Morgan, 1985). Positive clones were selected by immunofluorescence on cryostat sections of rat olfactory epithelium as also described previously (Hempstead and Morgan, 1983a, b). Only those clones that were found to be reactive with olfactory neurons (Hempstead and Morgan, 1985) are reported upon here, all being designated by the NEU prefix. A rabbit antiserum to OMP (Keller and Margolis, 1975) was a gift from Dr. F. Margolis of the Roche Institute.

Anesthetized male, Sprague-Dawley-derived, CD rats were subjected to unilateral olfactory bulbectomy at 5 weeks of age by the procedure of Whitten (1956). Gelfoam was used to fill the intracranial cavity to prevent inappropriate synapse formation between regenerating olfactory axons and neurons of the forebrain. After either 10 or 16 weeks post-operation, animals were sacrificed and prepared for immunocytochemistry as described previously (Hempstead and Morgan, 1983a). Animals were examined visually following perfusion in order to establish that bulbectomy had been successful. In animals of this age it was found that at least $90 \%$ of the olfactory bulb could be removed by simple aspiration, usually only a small spicule of degenerating bulb remaining compressed against the cribriform plate. The results reported here were from rats in which bulbectomy was essentially complete. In all experiments sagittal sections of olfactory epithelium were processed for double indirect immunofluorescence using one of the anti-neuronal monoclonal antibodies and anti-OMP (Hempstead and Morgan, 1983a). To compare the effect of bulbectomy on the expression of the various determinants, photographs were taken of regions spanning the central septum separating left from right (lesioned and unlesioned) epithelia.

\section{Results}

Unilateral olfactory bulbectomy results in a reduction in the number of OMP-positive neurons in the ipsilateral olfactory mucosa as evidenced by a reduction in the thickness of the OMP-reactive neuron layer (Figs. 1 to 4), confirming previous studies (Harding and Margolis, 1976; Monti Graziadei, 1980; Monti Graziadei, 1983). Immunocytochemical staining with two anti-neuronal monoclonal antibodies NEU-4 (Fig. 1) and NEU-9 (Fig. 4) also show a marked attenuation in the ipsilateral epithelium. However, whereas OMP staining of nerve bundles appears to become punctate and diffuse after bulbectomy (Figs. 1 to 3), loss of reactivity to both NEU-4 and NEU- 9 seems to be generalized (Figs. 1 and 4 , respectively). In contrast, a second group of monoclonal antibodies shows no appreciable loss of reactivity in the decentralized epithelium (Figs. 2 and 3). These results may thus reveal the presence of antigenic determinants the expression of which is dependent upon a functional connection with the olfactory bulb.

Bulbectomy also produces a number of organizational alterations in the olfactory neuroepithelium. As revealed in Figure 4, the decentralized epithelium contains a population of cells that span the mucosa and that are reactive with the NEU-9 monoclonal antibody. These cells have not been observed with other monoclonal antibodies, and their precise phenotype and lineage is not certain. By their position in the receptor neuron layer and their reactivity with an anti-neuronal antibody, we would suggest that they are some form of neuron. However, their gross morphology is more like that of a sustentacular cell (Fig. 4). These cells are occasionally observed in the normal epithelium, raising the possibility that bulbectomy has 

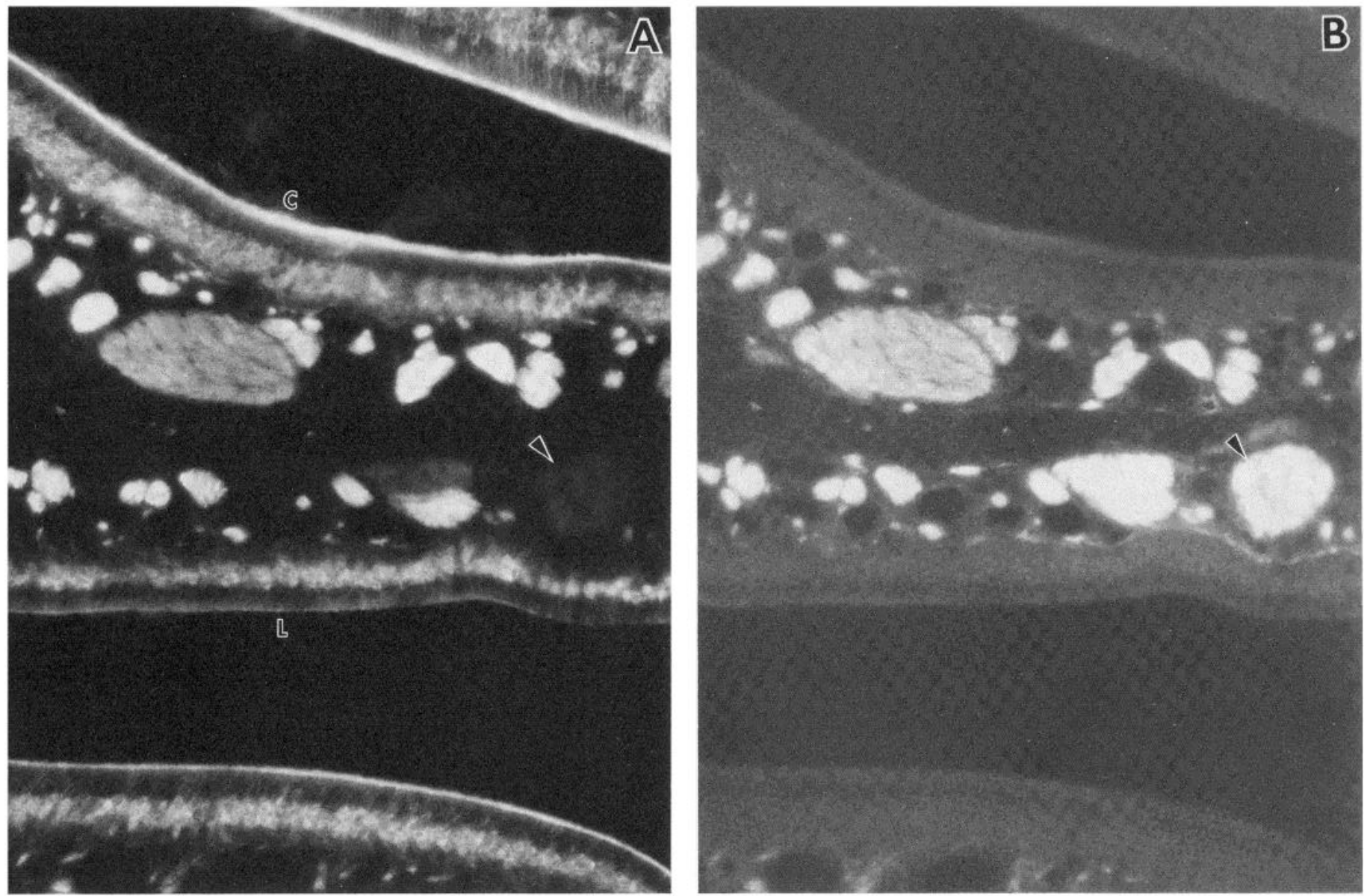

Figure 2. The staining characteristics of NEU-1 monoclonal antibody on rat olfactory epithelium. Details of sample preparation are as in the legend to Figure 1. A shows immunoreactivity with OMP antiserum and $B$ shows reactivity with NEU-1 monoclonal antibody. Control $(C)$ epithelium and lesioned epithelium $(L)$ are as described previously. The arrowhead shows the position of an OMP-poor nerve bundle that is reactive with the monoclonal antibody. There is no apparent difference between staining of normal or lesioned epithelium with the NEU-1 antibody. Magnification $\times 150$.

caused an alteration in the dynamics of differentiation of some cell type, possibly neurons, that results in a greater number of these cells now being present.

A second effect of bulbectomy on the organization of the olfactory epithelium is the presence of large OMP-positive structures at the level of the basal cell and the neuron layers (Fig. 5). Such structures are also reactive with anti-neuronal monoclonal antibodies (NEU-5 is depicted in Fig. 5) but are not stained with antibodies to sustentacular cells or basal cell layer (data not shown). The structures appear to be misplaced nerve bundles as is emphasized by a strong reactivity with the NEU-5 antibody (Fig. 5) which normally gives little staining of cell bodies but strong staining of nerve bundles (Hempstead and Morgan, 1985; Fig. 5). Serial sections of these structures reveal them to have a single connection to the lamina propria mucosae (Fig. 5, arrowhead 2), which we would suggest is the point at which a nerve bundle has inappropriately entered the mucosa. We do not know whether this situation results in any long-term pathological consequences for these animals.

\section{Discussion}

Removal of the target organ for olfactory receptor neurons results in alterations in neuronal differentiation such that there is a diminution in the number of cells expressing OMP (Figs. 1 to 4; Monti Graziadei, 1983). The immunocytochemical data presented here point to further antigenic determinants of receptor neurons the expression of which is linked to an intact connection with the olfactory bulb (Figs. 1 and 4). These determinants may be contrasted with others that do not respond tangibly to olfactory bulbectomy (Figs. 2 and 3). Further- more, it can be seen that those antibodies that react equally well with control and decentralized epithelia stain OMP-negative nerve bundles in the olfactory mucosa (Fig. 2). We have suggested that these axonal tracts are elements of the vomeronasal nerve (Hempstead and Morgan, 1985), and we have observed these fibers exiting the vomeronasal organ (unpublished observation). Thus, this class of anti-neuronal antibodies may recognize an antigenic determinant(s) common to both primary olfactory neurons and axons of the vomeronasal nerve that is not subject to regulation by the main olfactory bulb or accessory olfactory bulb, respectively.

Although there is much evidence to suggest some role, direct or indirect, of the olfactory bulb in the differentiation of receptor neurons and in the control of OMP expression (Harding and Margolis, 1976; Farbman and Margolis, 1980; Monti Graziadei, 1980; Chuah and Farbman, 1983), there is also much evidence prior to this study to indicate that the decentralized receptor neuron can still be differentiated from its basal cell precursor (Monti Graziadei, 1983; Morrison and Graziadei, 1983) and can express OMP in the absence of an olfactory bulb (Barber et al., 1982; Heckroth et al., 1983; Monti Graziadei, 1983). This has been taken to indicate that OMP expression is not directly controlled by the olfactory bulb but, rather, that the overall dynamics of neuronal turnover is increased by a lack of central nervous system interaction (Monti Graziadei, 1983). Thus, OMP may not be the marker of choice for olfactory receptor neurons when attempting to address questions relating to the direct influence of the olfactory bulb on gene expression in olfactory neurons. The antibodies used here may, however, prove useful in the latter context since they may represent probes with which to identify molecules 

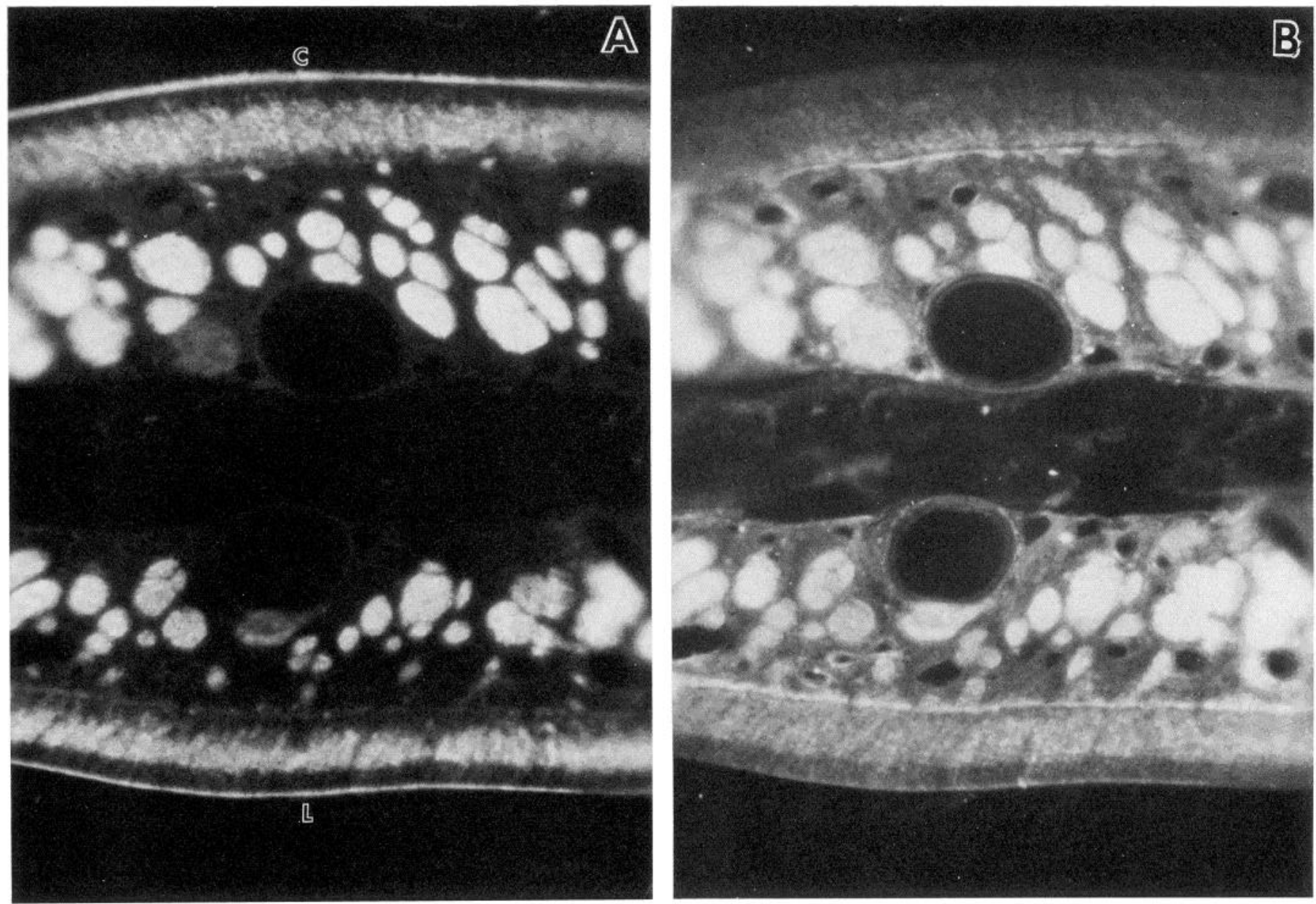

Figure 3. The staining characteristics of NEU-3 monoclonal antibody on rat olfactory epithelium. Details are as in the legends to Figures 1 and 2 . $A$ shows staining with anti-OMP and $B$ shows staining with NEU-3 monoclonal antibody on control $(C)$ and bulbectomized $(L)$ epithelium. Magnification $\times 150$.
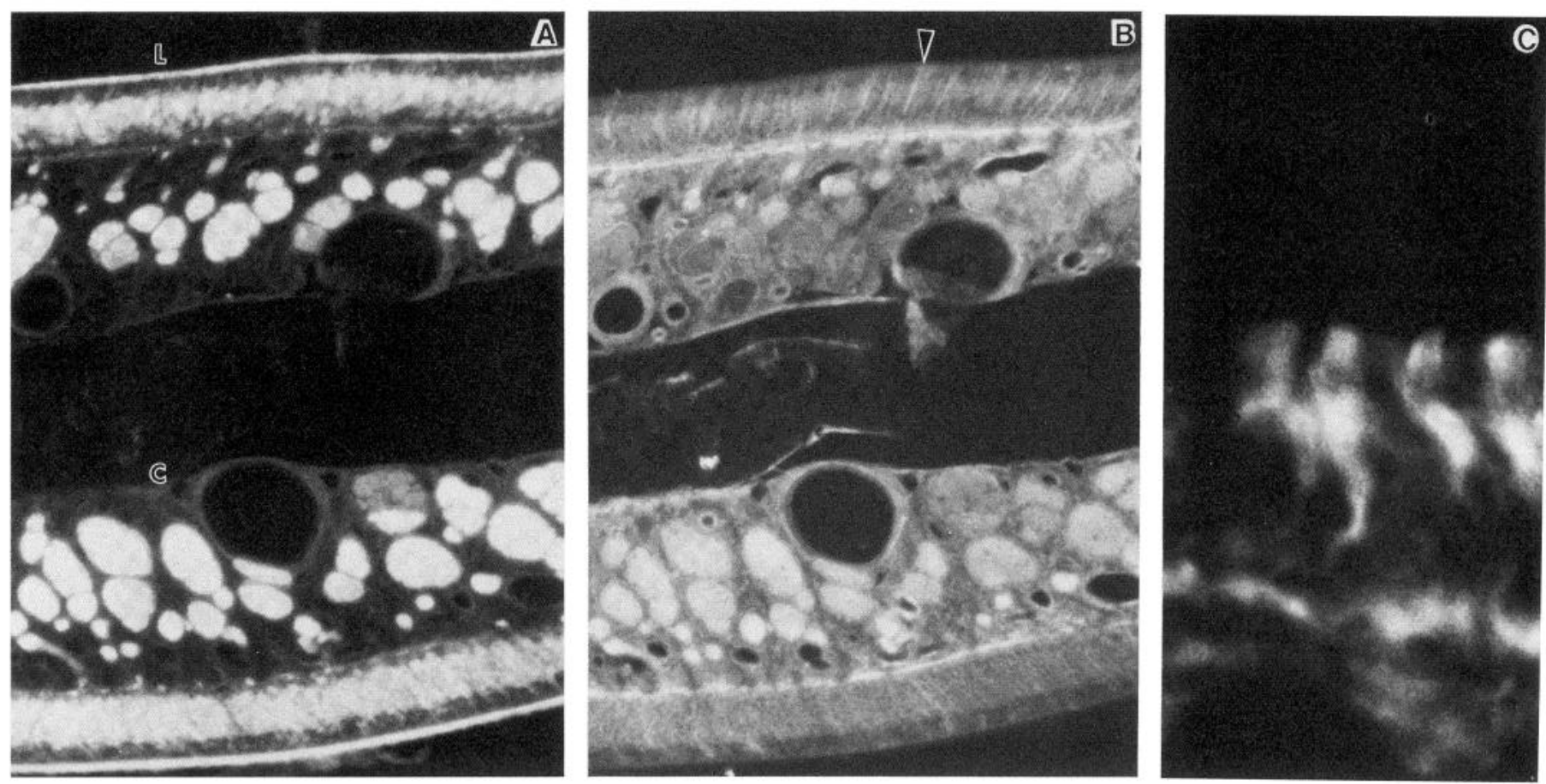

Figure 4. The staining characteristics of NEU-9 monoclonal antibody on rat olfactory epithelium. Procedural details are as in the legends to Figures 1 and 2. A shows immunoreactivity with OMP and $B$ shows reactivity with NEU-9 monoclonal antibody on control $(C)$ or decentralized $(L)$ epithelium. The arrowhead shows the position of cells stained by the NEU-9 antibody that are not seen in the control epithelium. Magnification $(A$ and $B) \times 150$. C depicts the staining of the novel cell type with the NEU-9 antibody at higher magnification $(\times 650)$. It may also be noted that the absence of the olfactory bulb causes a dramatic reduction in the staining of the olfactory epithelium with the NEU-9 monoclonal antibody. 

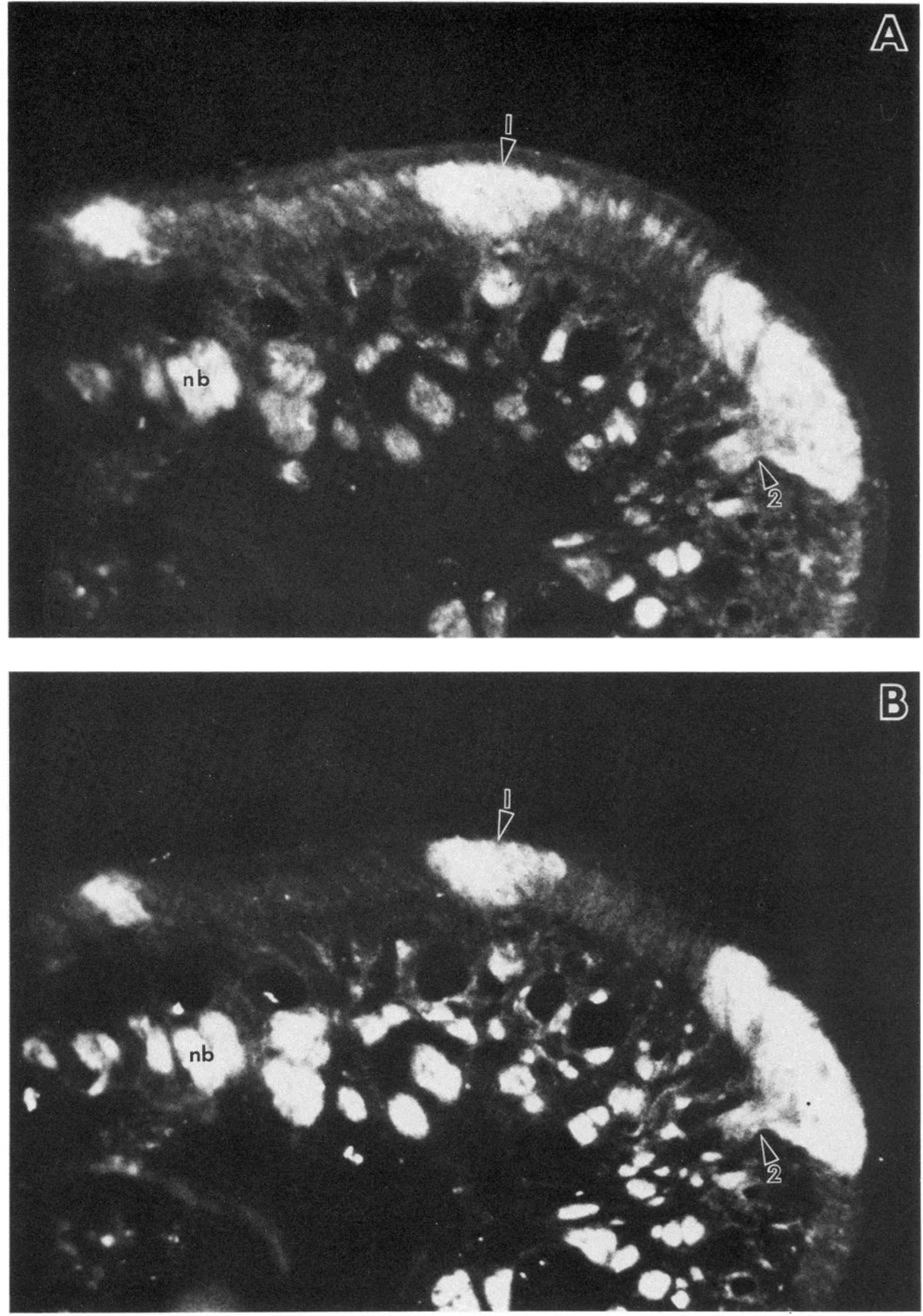

Figure 5. The staining of misplaced nerve bundles in decentralized olfactory epithelium by anti-OMP antiserum and the NEU-5 monoclonal antibody. A shows the staining of bulbectomized epithelium by an anti-OMP antiserum; B shows the same sections stained with the NEU-5 monoclonal antibody. Normally placed nerve bundles $(n b)$ may be seen in the lamina propria mucosae, while three abnormally positioned bundles or tangles (arrowhead 1) may be seen in the mucosa proper. The section has been selected to show what appears to be the point at which the bundle penetrates the lamina propria (arrowhead 2). Magnification $\times 150$. 
the expression of which is directly controlled by the olfactory bulb (Figs. 1 and 4).

The demonstration of the presence of a previously unreported cell type in the ipsilateral neuroepithelium (Fig. 4) may also relate to the notion of increased turnover of neuronal elements. Since these cells are present, albeit less frequently, in normal epithelium, an increased presence in bulbectomized epithelium may be reflecting enhanced production of these cells. This might be caused by a general overall increase in turnover through lowered elimination of these cells, or they may represent an alternative differentiated state of some cell type. Because of their location and reaction with an anti-neuronal antibody (Fig. 1), we feel that these cells are basically neuronal in phenotype. Although their gross morphology is rather more like that of a sustentacular cell (Fig. 4), they are neither positioned correctly nor do they react with a sustentacular cell-specific monoclonal antibody in either control or bulbectomized epithelia (Hempstead and Morgan, 1983a). During the preparation of this paper evidence has been presented for a subset of olfactory neurons that are rich in carbonic anhydrase (Brown et al., 1984). The position and morphology of these novel cells are similar to those reported here for NEU-9-positive cells. The data of Brown et al. (1984) also show primary olfactory neurons and a band of cells at about the level of the basal lamina to be carbonic anhydrase positive in a manner essentially identical to the distribution of NEU-9 labeling shown here (Fig. 4). To date we cannot show NEU-9 to be reactive with rat carbonic anhydrase by Western blotting (data not shown); demonstration of this point will estabish the identity of the two cell types.

One final observation merits further comment; that is, the presence of apparently misplaced axonal bundles in the decentralized epithelium (Fig. 5). All immunological evidence indicates these structures to be neuronal in nature (Fig. 5 , and data not shown) and no cell bodies are evident in conventionally stained sections of these structures (data not shown). Although it cannot be proven that these putative axonal tangles have entered the mucosa from the lamina propria mucosae, this would seem the most likely explanation since the single link point through the lamina propria appears to be on an axonal bundle (Fig. 5). The alternative would be a failure of many axons to tind their normal passage through the basement membrane and then to form these ball-like structures, finally to exit the mucosa at a single area. One fascinating point relating to these structures is that they apparently form within the receptor neuron and basal cell layers and do not penetrate the sustentacular cell layer (Fig. 5). This would indicate the existence of cell-cell recognition/association systems for olfactory neurons.

The monoclonal antibodies discussed here represent unique probes for the olfactory epithelium which may be used to establish whether the target olfactory bulb has any direct control upon gene expression in the olfactory receptor neuron. By next identifying the molecular nature of the antigenic determinants recognized by the various monoclonal antibodies, it may be possible to extend these observations to determine the mechanism by which the olfactory bulb might influence receptor neuron differentiation and to establish the temporal sequelae of induction of basal cells.

\section{References}

Barber, P. C., S. Jensen, and J. Zimmer (1982) Differentiation of neurons containing olfactory marker protein in adult rat olfactory epithelium transplanted to the anterior chamber of the eye. Nes rnoscience 7: ?687-2695.
Brown, D., L. -M. Garcia-Segura, and L. Orci (1984) Carbonic anhydrase is present in olfactory receptor cells. Histochemistry 80:307-309.

Chuah, M., and A. I. Farbman (1983) Olfactory bulb increases marker protein in olfactory receptor cells. J. Neurosci. 3: 2197-2205.

Constanzo, R. M., and P. P. C. Graziadei (1983) A quantitative analysis of changes in the olfactory epithelium following bulbectomy in the hamster. J. Comp. Neurol. 215: 370-381.

Farbman, A. I., and F. L. Margolis (1980) Olfactory marker protein during ontogeny: Immunohistochemical localization. Dev. Biol. 74: 205-215.

Ferriero, D., and F. L. Margolis (1975) Denervation in the primary olfactory pathway of mice. II. Effects on carnosine and other amine compounds. Brain Res. 94: 75-86.

Graziadei, P. P. C. (1973) Cell dynamics in the olfactory mucosa. Tissue Cell 5: 113-131.

Graziadei, P. P. C., and J. F. Metcalf (1971) Autoradiographic and ultrastructural observations on the frog's olfactory mucosa. Z. Zellforsch. Mikrosk. Anat. 116: 305-318.

Graziadei, P. P. C., and G. A. Monti Graziadei (1978) The olfactory system. A model for the study of neurogenesis and axon regeneration in mammals. In Neuronal Plasticity, C. Cotman, ed., pp. 131-153, Raven Press, New York.

Graziadei, P. P. C., R. R. Levine, and G. A. Monti Graziadei (1978) Regeneration of olfactory axons and synapse formation in the forebrain after bulbectomy in neonatal mice. Proc. Natl. Acad. Sci. U. S. A. 75: 52305234.

Harding, J., and F. L. Margolis (1976) Denervation in the primary olfactory pathway of mice. III. Effect of enzymes of carnosine metabolism. Brain Res. 110: 351-360.

Harding, J., P. P. C. Graziadei, G. A. Monti Graziadei, and F. L. Margolis (1977) Denervation in the primary olfactory pathway of mice. IV. Biocheinical and morphological evidence for neuronal replacement following nerve section. Brain Res. 132: 11-28.

Heckroth, J. A., G. A. Monti Graziadei, and P. P. C. Graziadei (1983) intraocular transplants of olfactory neuroepithelium in rat. Int. J. Dev. Neurosci. 1: 273-287.

Hempstead, J. L., and J. I. Morgan (1983a) Monoclonal antibodies to the rat olfactory sustentacular cell. Brain Res. 288: 289-295.

Hempstead, J. L., and J. I. Morgan (1983b) Fluorescent lectins as cellspecific markers for the rat olfactory epithelium. Chem. Sens. 8: 107-120.

Hempstead, J. L., and J. I. Morgan (1985) A panel of monoclonal antibodies to the rat olfactory epithelium. J. Neurosci. 5: 438-449.

Keller, A., and F. L. Margolis (1975) Immunological studies of the rat olfactory protein. J. Neurochem. 24: 1101-1106.

Margolis, F. L. (1975) Biochemical marker of the primary olfactory pathway: A model neural system. In Advances in Neurochemistry, B. W. Agranoff and M. H. Aprison, eds., pp. 193-246, Plenum Press, New York.

Monti Graziadei, G. A. (1983) Experimental studies on the olfactory marker protein. III. The olfactory marker protein in the olfactory neuroepithelium lacking connections with the forebrain. Brain Res. 262: 303-308.

Monti Graziadei, G. A., R. S. Stanley, and P. P. C. Graziadei (1980) The olfactory marker protein in the olfactory system of mouse during development. Neuroscience 5: 1239-1252.

Morrison, E. E., and P. P. C. Graziadei (1983) Transplants of olfactory mucosa in the rat brain. I. A light microscopic study of transplant organization. Brain Res. 279: 241-245.

Moulton, D. G. (1974) Cell renewal in the olfactory epithelium of the mouse. Ann. N. Y. Acad. Sci. 237: 52-61.

Nagahara, Y. (1940) Experimentelle Studien uber die histologischen Veranderungen des Geruchsorgans nach der Olfactoriusdurchschneidung. Beitrag zur Kenntnis des feineren Baus des Geruchsorgans. Jpn. J. Med. 5: 165-199.

Whitten, W. K. (1956) The effect of removal of the olfactory bulbs on the gonads of mice. J. Endocrinol. 14: 160-163. 